\title{
How Can We Act to Mitigate the Global Syndemic of Obesity, Undernutrition, and Climate Change?
}

\author{
William H. Dietz ${ }^{1}$ Sydney Pryor $^{2}$ \\ Published online: 9 February 2022 \\ (c) The Author(s), under exclusive licence to Springer Science+Business Media, LLC, part of Springer Nature 2022
}

\begin{abstract}
Purpose of Review The goal of this manuscript is to identify dietary and active transport strategies that reduce greenhouse gases and obesity, and thereby mitigate the effects of climate change on crop yields and micronutrient content.

Recent Findings This report builds on our earlier publication that described the Global Syndemic of Obesity, Undernutrition, and Climate Change. We focus here on the contributions that the USA makes to the Global Syndemic and the policy solutions necessary to reduce the effects of the transport and food and agriculture systems on greenhouse gas emissions and environmental degradation.

Summary A recent study suggests that people are interested and ready to address local solutions to climate change. Changing the individual behaviors that sustain the US transport and food and agriculture systems is the first step to the broader engagement necessary to build the political will that to achieve institutional, municipal, state, and federal policy.
\end{abstract}

Keywords Obesity $\cdot$ Undernutrition $\cdot$ Climate change $\cdot$ Syndemic $\cdot$ Active transport $\cdot$ Food and agriculture

\section{Introduction}

A syndemic is characterized as clusters of pandemics that occur within the same population at the same time and place, have an adverse biologic or social impact on each other, and are fostered by large scale social forces with an inequitable impact on marginalized populations [1].

In 2019, the three major pandemics that threatened the world's health were obesity, undernutrition, and climate change. In 2020, the emergence of the COVID-19 pandemic disproportionally affected people with obesity and added a pandemic of food insecurity to the existing pandemics. These twin clusters of pandemics constitute two distinct but related syndemics - a syndemic of obesity, undernutrition

This article is part of the Topical Collection on Etiology of Obesity

William H. Dietz

bdietz@gwu.edu

$1 \quad$ Milken Institute School of Public Health, George Washington University, 950 New Hampshire Ave, Washington, DC 20052, USA

2 Redstone Global Center for Prevention and Wellness, Milken Institute School of Public Health, The George Washington University, Washington, DC 20052, USA and climate change, and an overlapping syndemic of COVID-19, obesity, and food insecurity.

These twin syndemics have an adverse impact on each other through their impact on the food supply and their inequitable impacts on food insecurity and malnutrition. As we consider later in this manuscript, climate change reduces crop yields and the micronutrient content of crops, all of which increase the likelihood of food insecurity and undernutrition. In the accompanying paper [2], we consider COVID-19 and its adverse effects on employment and higher prices of food associated with disruptions in the food supply chain as contributors to food insecurity and increased rates of obesity.

In this manuscript, several observations prompted us to focus on US strategies to address the Global Syndemic of Obesity, Undernutrition, and Climate Change [•3]. First and foremost, the USA is the second leading contributor to GHG emissions behind China, and we are the fourth leading contributor to global GHG emissions on a per capita basis, behind China, India, and Brazil [4]. Successful efforts to reduce the US contribution to GHGs will have a major impact on global climate change and food insecurity. Second, prioritization of solutions in the USA may differ from global solutions. For example, agriculture and transportation contribute $10 \%$ and $30 \%$ of US GHG emissions, 
respectively [5], whereas globally, agriculture and transportation contribute $24 \%$ and $14 \%$ of GHGs, respectively [5]. Although some of the solutions to the Global Syndemic may be generalizable globally, many of the policy initiatives are US-centric.

\section{Global Disease Burden and Costs of Obesity, Undernutrition, and Climate Change}

In 2010, malnutrition in all its forms, which included undernutrition, stunting, wasting, micronutrient deficiencies, and obesity, were estimated to cost $\$ 3.5$ trillion/year, equal to $2-3 \%$ of the global gross domestic product (GDP) [6-8]. Obesity has increased rapidly across the globe in children, adolescents [9] and adults [10], and no country has reported a significant decrease in prevalence. The disease affects over 2 billion people worldwide. In 2019, the global prevalence of stunting was estimated to affect 150 million children, with a higher prevalence in south Asia and sub-Saharan Africa, and the prevalence of wasting was estimated to affect 50 million children worldwide [11, 12]. The gradual decline in stunting has been matched by increases in obesity $[9,12]$. In 2016, two billion people suffered from micronutrient deficiencies, and 800 million people were chronically undernourished [13]. By 2050, the predicted costs of climate change are a reduction of 5-10\% of the world's GDP; costs in low-income countries in Asia, the Middle East, and Africa may exceed $15 \%$ of their GDP [14].

\section{The Global Syndemic of Obesity, Undernutrition, and Climate Change: Interactions}

In 2019, the Lancet Commission on Obesity published its report on the Global Syndemic of Obesity, Undernutrition, and Climate Change [•3]. Because of its substantial, pervasive, and ubiquitous impact on health, we considered climate change a pandemic. Multiple interactions between obesity, undernutrition, and climate change are shown in Table 1. For example, it is now clear that in low- and middle-income countries, obesity, stunting, and food insecurity occur in the same children and same population - a double burden of malnutrition $[12,15,16]$. The agricultural system accounts for approximately $10 \%$ of greenhouse gas emissions (GHGs) in the USA and $20-30 \%$ of GHGs globally $[\bullet 3, \bullet 17]$ Within the agricultural system, cattle production for meat and dairy generates methane, which accounts for over $80 \%$ of agricultural GHGs, and is 80 times more potent than $\mathrm{CO}_{2}$ [18]. Beef consumption contributes to obesity, colon cancer, and cardiovascular disease $[\bullet 3,19,20]$. In addition, obesity appears to make a small but significant contribution to climate change [21-25].

The global warming that is a consequence of increased GHGs increases atmospheric water uptake which in turn increases the likelihood of severe hurricanes, flooding rains, fires, and drought [26]. Furthermore, the increase in GHGs has increased mean atmospheric temperatures which have already led to an increase in heat-related mortality [27] and wild fires [28]. Climate change is expected to increase the fluctuation of weather, increasing rainfall in areas where rain is common, and increasing dryness in already arid areas [29]. As illustrated in Fig. 1, increased atmospheric $\mathrm{CO}_{2}$ decreases crop yields and reduces the concentration of essential nutrients such as protein, iron, and zinc in selected crops $[29, \bullet 30,31]$. Increased atmospheric $\mathrm{CO}_{2}$ also increases ocean acidification with adverse effects on corals and fisheries. These effects are inequitably distributed, and are already having a greater impact on poor populations, especially those in the global south.

The use of fossil fuels for transportation systems also increases GHGs, rates of obesity, and ill health. Car use is associated with reduced physical activity and increased rates of obesity [32], and changes from automated to active transport like walking and biking have been associated with increased physical activity and declines in the prevalence of obesity [33, 34].

A systematic review and meta-analysis has demonstrated that poor air quality, secondary to motorized transit, is associated with obesity in children [35, 36] and adults [37]. Poor air quality and particulate matter pollutants are associated with pulmonary diseases such as asthma [38], which may contribute to the association of asthma with obesity [35, $39,40]$. The disparate effects of air quality on obesity and asthma in minority populations may be exacerbated by the co-location of coal burning plants and truck depots in underserved neighborhoods.
Table 1 Examples of the interactions of obesity, undernutrition and climate change
- Obesity, stunting, and food insecurity in the same children and same population

- Car use, GHG emissions, inactivity, and obesity

- Cattle production, GHG emissions, meat consumption and obesity, diabetes, colon cancer and cardiovascular diseases

- Overproduction and overconsumption of ultra-processed foods and obesity

- Increased GHGs reduce crop yields and micronutrient content of crops which contribute to food insecurity and undernutrition 


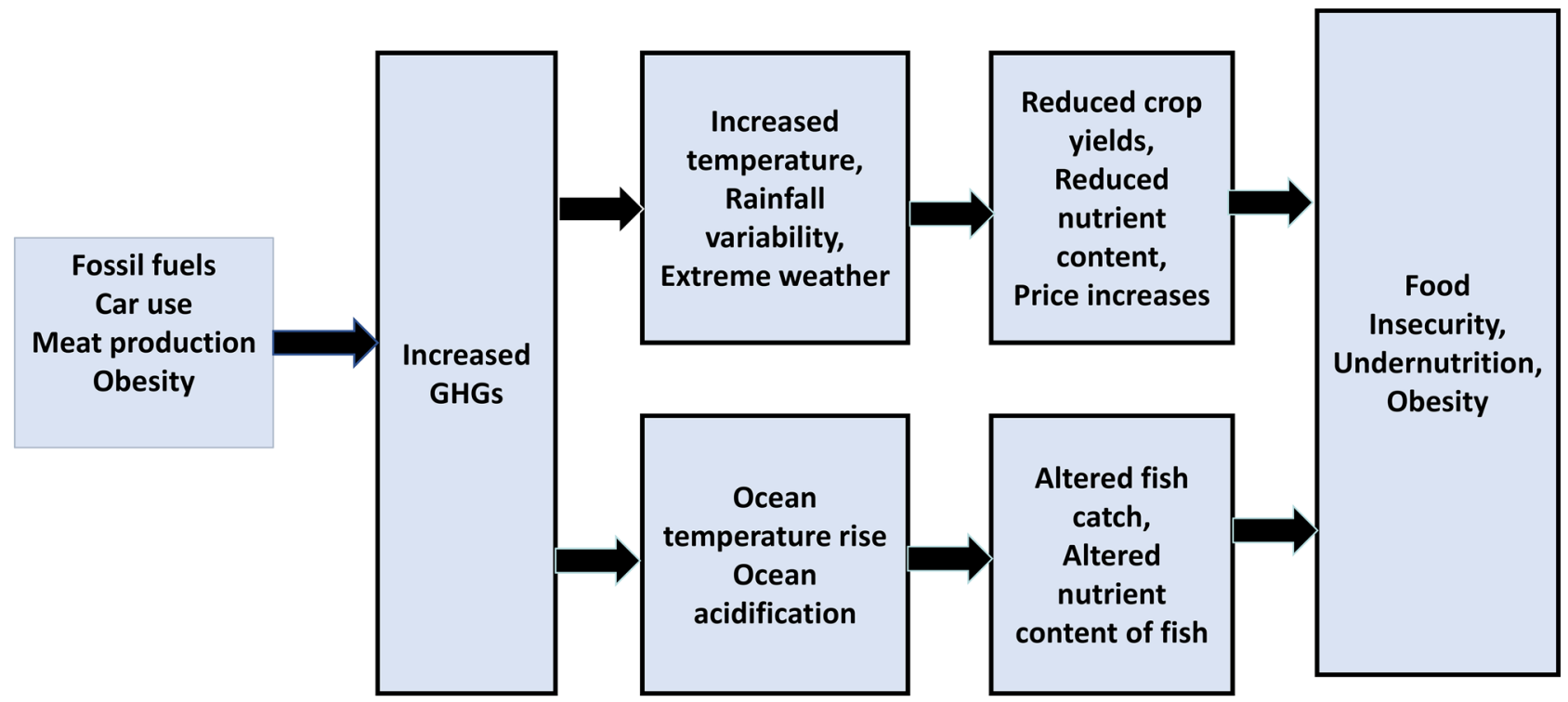

Fig. 1 Pathways by which increased greenhouse gases affect food insecurity and undernutrition. Adapted from Myers et al., reference [•30]

\section{Examples of Triple Duty Solutions to the Global Syndemic of Obesity, Undernutrition, and Climate Change}

The Lancet Commission on Obesity suggested 18 actions to mitigate the Global Syndemic, including actions for all, for nations and municipalities, civil society, funders, and international agencies [•3]. In the sections below, we propose comprehensive triple duty solutions that focus on changes in the deeper US drivers of the transportation and agricultural systems that mitigate the Global Syndemic.

Sustainable food and agricultural systems. The Lancet Commission on Obesity focused largely on GHG emissions. However, how the agricultural production system and food consumption patterns affect land use, water consumption, and environmental degradation indicate the need to focus on sustainability of the food system going beyond its effects on GHGs. Sustainable diets have been defined as "diets with low environmental impacts which contribute to food and nutrition security and to healthy life for present and future generations. Sustainable diets are protective and respectful of biodiversity and ecosystems, culturally acceptable, accessible, economically fair and affordable; nutritionally adequate, safe and healthy, while optimizing natural and human resources" [41]. Stated another way, a sustainable diet must foster both human and planetary health.

Beef is by far the biggest source of agricultural GHGs, and the continued production of beef and dairy cattle is unsustainable. The emissions/gram of beef protein are almost 250 times those from the production of legumes, and 20 servings of vegetables have fewer GHG emissions than one serving of beef [42]. The demand for beef, seafood, poultry, and pork by the 15 richest nations, the USA among them, may be $750 \%$ greater than the 24 poorest nations [42]. These observations impose a disproportionate responsibility on the USA to lead efforts to change dietary practices to lower our impact on GHG generation. Those efforts should begin with a reduction in beef consumption.

Cattle production has been estimated to account for $70 \%$ of global agricultural land, and a third of arable land is devoted to the production of fodder for animal feed [18]. Irrigation for cattle feed uses $23 \%$ of national water consumption, $32 \%$ of consumption in the western USA, and $79 \%$ of consumption in the Colorado River basin [43]. The widespread drought that is now affecting many of the western states indicates that continued beef and fodder production is unsustainable. It seems obvious that one of the solutions to the western drought would be to decrease the water allotted for the irrigation of fodder. Such reductions would likely require a decrease in cattle production which would increase the price and reduce the consumption of beef. Not surprisingly, this scenario has received little attention.

The production of fodder in western states also contributes to an unsustainable future. Approximately $30 \%$ of nitrogen fertilizer for corn and soy crops is lost as run-off in surface water or groundwater [44]. This process has been accelerated by increased precipitation related to climate change. The nitrogen runoff is carried by the Mississippi River and its tributaries into the Gulf of Mexico where eutrophication decreases the oxygen content with a negative effect on fisheries. In 2017, the resultant "dead zone" was the size of New Jersey [44]. 
Given the impact of beef consumption, reductions in meat consumption will have a quadruple duty effect; reduced consumption will reduce production, which will reduce GHG generation and thereby preserve or reduce the impact of GHGs on crop volume, the micronutrient content of foods, and undernutrition [45]. The reduction in fodder production and the introduction of other farming techniques will reduce the eutrophication in the Gulf, improve fisheries, and thereby reduce the food insecurity of the fisheries supply chain workforce.

The EAT-Lancet Commission has explored in detail the magnitude of the changes necessary to attain sustainable food systems and the planetary boundaries necessary to reduce the adverse impact of environmental damage caused by food production [46]. The Commission also recognized that healthful diets incorporate plant-based protein sources such as soy, legumes, and nuts with occasional intakes of poultry, eggs, and very low intakes of red meat; unsaturated fat from plants, carbohydrates from whole grains and sugar intake less than $5 \%$ of calories; at least five servings of fruits and vegetables daily; and moderate dairy consumption [46]. Shifts to these dietary patterns are consistent with the Dietary Guidelines for Americans 2020-2025 [47] and can be achieved in a variety of diets, consistent with multiple cultural and agricultural systems. However, a major challenge with the EAT-Lancet Commission's recommendations is that the projected costs exceed the per capita income for an estimated 1.5 billion people [48].

Predominantly plant-based diets are better for the health of humans and the planet. Diets with greater proportions of fruits, vegetables, nuts grains, and reduced proportions of red meat, such as the Mediterranean, pescatarian, and vegetarian diets, significantly lower the risks of chronic diseases such as type 2 diabetes, cancer, and coronary and all-cause mortality [42, 46, 49]. Predominantly plant-based diets also appear associated with decreased weights and a lower prevalence of obesity [50, 51]. Furthermore, diets with reduced quantities of meat, such as vegetarian and the Mediterranean diet, have a lower environmental impact and are more sustainable than the usual western diet [52]. The largest planetary benefits will likely result from changes in high- and middle-income countries [49, 53].

Sustainable active transport systems. Like the food and agriculture system, transportation systems should also be sustainable. Our definition of a sustainable transport system is adapted from the FAO definition for sustainable diets [41]. Sustainable transport systems are those with low environmental impact that contribute to active transport for present and future generations. Sustainable transport systems protect and respect biodiversity and ecosystems; are culturally acceptable, accessible, economically fair, and affordable; and promote safe and healthy opportunities for active transport while optimizing natural and human resources. The strategies to foster active transport that we outline below also reflect the elements necessary for a sustainable transportation system.

In 2020, $26 \%$ of total US energy was used for transportation, and gasoline accounted for $56 \%$ of total transportation fuels [54]. The use of fossil fuels is sustained by subsidies that are estimated at $\$ 62 \mathrm{~B} /$ year [55]. The combined federal and state taxes on gasoline and diesel fuels are approximately $\$ 0.48$ and $\$ 0.56$ per gallon, respectively [56], and the federal gasoline tax has not been increased since 1993 [57]. Because the federal gas tax is rolled into the Highway Trust Fund, the combination of subsidies and low taxes sustains motorized transport. One potential approach to reduce the GHGs that result from car use is to eliminate subsidies for the fossil fuel industry and increase the federal gasoline and diesel taxes. Increased taxes and reduced subsidies will increase the cost of fuel which will lead to decreased car use, decreased GHGs and increased active transport. Although electrification of transport systems including cars will reduce reliance on fossil fuels, it will not necessarily increase physical activity or reduce obesity. However, active transport will reduce air pollution, particularly $\mathrm{PM}_{2.5}$, which may also reduce obesity and other illnesses related to poor air quality [58]. For example, the reduction in car use associated with the 1996 Olympics in Atlanta was associated with major decreases in ozone and substantial reductions in emergency room visits and hospitalizations for asthma [59]. Reduced motorized transport will also improve health equity by reducing the exposure of marginalized communities to poor air quality. Investments in public transport increase physical activity, because people have to walk to access public transport, and walk or bike from their bus or metro stop to their destination [60]. The net effect of these changes will be to reduce and mitigate obesity and reduce GHGs.

Community infrastructure offers a second strategy to increase active transport. Creation of and access to places for physical activity are recommended strategies to increase physical activity. Environmental determinants include communityand street-scale urban design, as well as active transport policies that promote walking and cycling [61]. Reduced obesity has been associated with physical activity, community design, and time spent in cars [32]. A combination of eight integrated combined interventions that increase active transport, while reducing car use include making destinations more accessible, developing optimal levels of residential density with reducing distance to public transport, connecting neighborhoods to places of employment, and providing safe, affordable, and accessible public transportation options [62]. A study of physical activity in 14 high- and middle-income countries confirmed that residential density, intersection density, public transport density, and number of parks were significantly 
positively and linearly related to physical activity measured by accelerometry. Residents who lived in the most activity friendly neighborhoods spent $68-89$ min more in physical activity/week than those in least activity friendly neighborhoods [63, 64]. An additional benefit of neighborhood design is that parks and greenspace not only increase physical activity and reduce obesity [65] but they are also carbon sinks that act to reduce GHGs. These effects can be expected to have a sextuple duty effect: they will reduce car use, increase active transport, reduce and mitigate obesity, reduce GHGs, provide a carbon sink, and improve air quality [66]. The reduction in GHGs will improve crop yields and micronutrient content, thereby reducing food insecurity and undernutrition.

\section{Costs}

Actions to change these systems might be prompted by recognizing that the food and agriculture and transportation systems are heavily subsidized and that these subsidies sustain the adverse impact of these systems on climate change and the environment. The costs of food and transportation do not reflect their true costs or externalities. For example, a new report from the Rockefeller Foundation $[64, \bullet 67]$ estimated that the current costs of food along the supply chain from food production to food retail were \$1.1 trillion annually. However, the estimated costs of illness, water and air pollution, and GHGs add an additional cost of $\$ 2.1$ trillion per year. Most of these costs are attributable to the effects on human health and the environment; obesity accounts for \$359 B, and other chronic diet-related diseases like cancer and cardiovascular disease account for an additional \$604B of the \$1.1 T in total health costs. The environmental effects of food production account for another $\$ 442$ billion, and GHGs from livestock production and crop cultivation are responsible for $\$ 300 \mathrm{~B}$. A disproportionate share of these costs is borne by communities of color and workers along the food supply chain [•67]. A similar analysis of the transportation system that accounted for the externalities of the costs of illness associated with the displacement of active transport by car use, the production of GHGs from car use, and the methane released as a side product of oil production would likely produce similar costs [62, 64]. Recognition that these costs ultimately tie to individual behaviors, like beef consumption or car use, is a critical goal.

\section{The Development of Political Will}

The syndemic perspective offers an opportunity to develop comprehensive double- and triple-duty solutions that mitigate several of these pandemics simultaneously. We have suggested some of the policy solutions that begin to achieve these goals. Our proposed policy solutions constitute what must be done. However, how to develop the political will necessary to implement these policies presents a more formidable task. For example, the 2015-2020 Dietary Guidelines Advisory Committee recommended that sustainability should be considered as a criterion for dietary guidance [68]. In response to strenuous and vocal objections and lobbying by the meat industry, the Secretaries of the Departments of Health and Human Services and Agriculture declared that the Dietary Guidelines for Americans (DGAs) would not include considerations of sustainability [69]. As a result, sustainability was not included in the scope of work for the 2020-2025 DGAC.

The objections raised to the inclusion of sustainability in the DGAs provide only an inkling of the response we might anticipate to more aggressive efforts to change beef consumption. For example, if the subsidies for commodity crops used to feed cattle are removed, the fast-food industry will not likely embrace the increase in the price of burgers that will follow, particularly if price increases decrease demand. The costs of gasoline are kept low by subsidies for the production of oil and the resistance to increasing the federal gas tax [70]. Predictably, efforts to reduce or eliminate subsidies or increase taxes will be met with major concerted resistance by the fossil fuel industry and objections by consumers when the price at the pump is increased. Both circumstances will also be disproportionally experienced by low-income populations. These regressive effects can be avoided if the cost savings from the elimination of subsidies and increased revenue from gasoline taxes are redirected to strategies that improve access and lower the costs of healthier alternatives, such as subsidies for the production of plant-based foods, incentives for active transport, or increased investment in public transportation. Redirecting revenue to build alternative transport systems would provide a double duty solution - reduced GHG generation and increased active transport with improved cardiovascular health and reduced obesity. The policy strategies that address climate change also represent stealth interventions to increase physical activity, improve diets, and reduce obesity [71]. Overcoming the resistance to policies that reduce climate change and environmental degradation requires the development of political will.

A recent nationally representative survey of the opinions of US adults related to climate change suggests that people may be ready to act and may only need strategies by which they can engage [72]. Almost $75 \%$ of respondents thought that global warming was happening, and $60 \%$ believed that global warming is caused by humans. Two-thirds of respondents said that global warming was extremely or somewhat important to them personally, and approximately the same number felt a personal responsibility. Sixty-eight percent of respondents felt it was not too late to do something about global warming, and $67 \%$ thought that global warming is an 
agriculture and food issue. Surprisingly, only $36 \%$ discussed their concerns with family and friends. Although responses were not stratified by age, it is likely that younger individuals were more concerned than older adults.

Press coverage of the (un)natural disasters of fires in California, Oregon, and Australia, the droughts that have fostered and accompanied those fires, and the flooding rains in Houston and most recently in Germany and China have linked these catastrophic events to climate change. The next step is to link these events to the multiple individual, institutional, and corporate practices that generate GHGs and unsustainable systems. In our view, changes to these practices can begin at the individual and institutional level and then move to local policy initiatives that ultimately extend to the state and federal level. Although individual behavior changes will have an extremely small impact on GHGs, the changes represent the first step to a broader engagement with policy making. The challenge is how to help people understand that their actions connect to these broader systems, how these systems connect to climate change and sustainability, and how to mobilize in the face of political resistance $[\bullet 3]$. The evidence is abundantly clear that our agriculture and transportation systems are major contributors to the generation of GHGs and environmental degradation. Action steps for the individual include reducing meat consumption, consuming a more plant-based diet, and using active transport or public transportation. At the community level, the lack of infrastructure that supports local or regional food systems, and active or public transportation can then become a target for change.

The same pressures that university students are applying to achieve divestment of fossil fuels can be extended to other climate friendly institutional policies. For example, policies that require that a proportion of purchased food be sustainably produced, or that the costs of public transportation be reimbursed or deducted, or that a motorized fleet be replaced with hybrid or electric cars all represent examples of climate and health friendly institutional policy initiatives. Residential zoning that mandates trees, green space, and sidewalks and bike paths that lead to places where people want to go, and public transportation that connects where people live to where they work begins to engage people in a relevant political process.

Many groups are actively engaged in strategies that address climate change and sustainability, but often lack common targets. This lack of agreement is a barrier to a more unified movement. A focus on sustainability can begin to link civil society, public health, local food movements, and initiatives that foster local and regional food systems [73]. Local initiatives can expand to broader networks to share insights, innovations, and successes. A good example is the C40 initiative funded by Bloomberg Philanthropies, which has established networks of cities that address food systems, mass transit, and active transport [74].
The effects of climate change on health have received less emphasis that the effects of climate change on the planet. The policy action agenda provides a good example of how a coalescence of institutions can take collective action. Almost 200 health and healthcare organizations have signed on to a policy action agenda that includes active transportation and sustainable, healthy, and resilient farms and food systems [75]. The latter policy includes a recommendation for plantbased diets and reduced consumption of red and processed meat by providing meat-free alternatives in school meals. The extent to which these policy recommendations have been adopted is uncertain.

As the efforts to change policies and practices at the individual, institutional, municipal, and state level progress, it is essential to build monitoring systems to assess progress and assure accountability. The 2018 report of the Lancet Countdown on Health and Climate Change suggested a number of indicators, many directly related to the syndemic [76]. These included measures of food security and undernutrition, such as crop yields and nutrient quality, exposure to ambient air pollution as a measure of shifts in transport, sustainable travel infrastructure, ruminant meat for human consumption, and fossil fuel subsidies, which would include gasoline taxes. Some of these measures can be collected locally and shared nationally, but the aggregation of these measures will require a central monitoring agency. To promote equity in these policies and practices, particular attention should be accorded to measures applicable to marginalized populations which are at the greatest risk of adverse exposures.

\section{Conclusion}

Because the transport and food and agricultural systems in the USA make major contributions to greenhouse gas emissions and environmental degradation, we have a moral imperative to take steps to change the drivers of these systems. Although efforts are underway to change policy at the national level, these efforts have been met with substantial resistance. In addition, the most challenging policy initiatives, such as those that remove subsidies for fossil fuels and commodity crops or increase taxes on gasoline, will not be accomplished without reducing individual and population demand for beef and car use. The most sustained behavior changes have occurred among participants in religious or social movements [71]. It is our hope that the passions ignited by the climate crisis among young people are approaching those that have fueled other movements. An initial focus on what we can personally change recognizes the urgency of action, driven by an awareness of the consequence of inaction. If we do nothing, it is clear that the effects of climate change on the planet and human health will become irreversible. 


\section{Compliance with Ethical Standards}

Human and Animal Rights and Informed Consent This article does not contain any studies with human or animal subjects performed by any of the authors.

\section{References}

Papers of particular interest, published recently, have been highlighted as:

- Of importance

$\bullet$ Of major importance

1. Mendenhall E, Singer M. What constitutes a syndemic? Methods, contexts, and framing from 2019. Curr Opin HIV AIDS. 2020;15(4):213-7.

2. Pryor S, Dietz W. Current Obesity Reports. 2021.

3. Swinburn BA, Kraak VI, Allender S, Atkins VJ, Baker PI, Bogard JR, et al. The global syndemic of obesity, undernutrition, and climate change: the Lancet Commission report. Lancet. 2019;393(10173):791-846. Key reference that provides a innovative view of the interactions of obesity, undernutrition and climate change that enables triple duty solutions.

4. Kim BF SR, Scatterday AP, Fry JP, Synk CM, Cebron SR, MeKonnen MM, Hoekstra AY, de Pee S, Bloem MW, Neff RA, Nachman KE. Country-specific dietary shifts to mitigate climate and water crises. Glob Environ Change. 2020;62:101926.

5. Environmental Protection Agency. Total U.S. Greenhouse gas emissions by economic sector in 2017. https://www.epa.gov/ ghgemissions/sources-greenhouse-gas-emissions. Accessed 28 Oct 2019.

6. Food and Agriculture Organization of the United Nations. The state of food and agriculture 2013. Rome, Italy: FAO; 2013.

7. Lehnert T, Sonntag D, Konnopka A, Riedel-Heller S, Konig HH. Economic costs of overweight and obesity. Best Pract Res Clin Endocrinol Metab. 2013;27(2):105-15.

8. Dobbs R, Sawers C, Thompson F, Manyika J, Woetzel J, Child $\mathrm{P}$, et al. How the world could better fight obesity. New York: McKinsey Global Institute; 2014.

9. NCD Risk Factor Collaboration (NCD-RisC). Worldwide trends in body-mass index, underweight, overweight, and obesity from 1975 to 2016: a pooled analysis of 2416 population-based measurement studies in 128.9 million children, adolescents, and adults. Lancet. 2017(390):2627-42.

10. NCD Risk Factor Collaboration (NCD-RisC). Trends in adult body-mass index in 200 countries from 1975-2014: a pooled analysis of 1698 population-based measurement studies with 19.2 million participants. Lancet. 2016;387(10026):1377-96.

11. UNICEF. The State of the World's Children 2019. Children, food and nutrition: growing well in a changing world. New York: UNICEF; 2019.

12. Black RE, Victora CG, Walker SP, Bhutta ZA, Christian P, de Onis M, et al. Maternal and child undernutrition and overweight in low-income and middle-income countries. Lancet. 2013;382(9890):427-51.

13. International Food Policy Research Institute. Global Nutrition Report 2016. From Promise to Impact: Ending Malnutrition by 2030. Washington, DC: International Food Policy Research Institute; 2016.

14. Giuo J, Kubli J, Saner P. The economics of climate change: no action not an option. Zurich, Switzerland: Swiss Re Institute; 2021.
15. Tzioumis E, Kay MC, Bentley ME, Adair LS. Prevalence and trends in the childhood dual burden of malnutrition in low- and middle-income countries, 1990-2012. Public Health Nutr. 2016;19(8):1375-88.

16. Popkin BM, Corvalan C, Grummer-Strawn LM. Dynamics of the double burden of malnutrition and the changing nutrition reality. Lancet. 2020;395(10217):65-74.

17. Vermeulen SJCB, Ingram JSI. Climate change and food systems. Annu Rev Environ Resour. 2012;37:195-222. This article focuses on the substantial impact of climate change on food systems.

18. Ripple W, Smith P, Haberl H, Montzka S, McAlpine C, Boucher D. Ruminants, climate change and climate policy. Nat Clim Change. 2014;4(1):2-5.

19. Wang Y, Beydoun MA. Meat consumption is associated with obesity and central obesity among US adults. Int $\mathrm{J}$ Obes (Lond). 2009;33(6):621-8.

20. Godfray HCJ, Aveyard P, Garnett T, Hall JW, Key TJ, Lorimer $\mathrm{J}$, et al. Meat consumption, health, and the environment. Science. 2018;361(6399).

21. Jacobson S, King D. Measuring the potential for automobile fuel saving in the U.S.: the impact of obesity. Transp Res Pt D Transp Environ. 2009;14(1):6-13.

22. An R, Ji M, Zhang S. Global warming and obesity: a systematic review. Obes Rev. 2018;19(2):150-63.

23. Gryka A, Broom J, Rolland C. Global warming: is weight loss a solution? Int J Obes (Lond). 2012;36(3):474-6.

24. Edwards P, Roberts I. Population adiposity and climate change. Int J Epidemiol. 2009;38(4):1137-40.

25. Magkos F, Tetens I, Bugel SG, Felby C, Schacht SR, Hill JO, et al. The environmental foodprint of obesity. Obesity. 2020;28(1):73-9.

26. Lesk C, Rowhani P, Ramankutty N. Influence of extreme weather disasters on global crop production. Nature. 2016;529(7584):84-7.

27. Vicedo-Cabrera AM, Scovronick N, Sera F, Royé D, Schneider $\mathrm{R}$, Tobias A, et al. The burden of heat-related mortality attributable to recent human-induced climate change. Nat Clim Change. 2021;11(6):492-500.

28. Xu R, Yu P, Abramson MJ, Johnston FH, Samet JM, Bell ML, et al. Wildfires, global climate change, and human health. N Engl J Med. 2020;383(22):2173-81.

29. Fanzo J, McLaren R, Davis C, Choufani J. Climate change and variability: what are the risks fo nutrtion, diets, and food systems? Washington, DC: International Food Policy Research Institute; 2017. Contract No.: Discussion paper 01645.

30. Myers SS, Smith MR, Guth S, Golden CD, Vaitla B, Mueller ND, et al. Climate change and global food systems: potential impacts on food security and undernutrition. Annu Rev Public Health. 2017;38:259-77. Provides a useful analysis of how increasing $\mathrm{CO} 2$ levels affect fisheries, and the yields and micronutrient content of crops.

31. Myers SS, Zanobetti A, Kloog I, Huybers P, Leakey AD, Bloom $\mathrm{AJ}$, et al. Increasing $\mathrm{CO} 2$ threatens human nutrition. Nature. 2014;510(7503):139-42.

32. Frank LD, Andresen MA, Schmid TL. Obesity relationships with community design, physical activity, and time spent in cars. Am J Prev Med. 2004;27(2):87-96.

33. Flint E, Webb E, Cummins S. Change in commute mode and body-mass index: prospective, longitudinal evidence from UK Biobank. Lancet Public Health. 2016;1(2):e46-55.

34. Martin A, Panter J, Suhrcke M, Ogilvie D. Impact of changes in mode of travel to work on changes in body mass index: evidence from the British Household Panel Survey. J Epidemiol Community Health. 2015;69(8):753-61. 
35. Parasin N, Amnuaylojaroen T, Saokaew S. Effect of air pollution on obesity in children: a systematic review and meta-analysis. Children (Basel). 2021;8(5):327.

36. Vijayakanthi N, Greally JM, Rastogi D. Pediatric obesity-related asthma: the role of metabolic dysregulation. Pediatrics. 2016;137(5).

37. Tamayo-Ortiz M, Tellez-Rojo MM, Rothenberg SJ, GutierrezAvila I, Just AC, Kloog I, et al. Exposure to PM2.5 and obesity prevalence in the greater Mexico city area. Int J Environ Res Public Health. 2021;18(5):2301.

38. Guarnieri M, Balmes JR. Outdoor air pollution and asthma. Lancet. 2014;383(9928):1581-92.

39. Beuther DA, Weiss ST, Sutherland ER. Obesity and asthma. Am J Respir Crit Care Med. 2006;174(2):112-9.

40. Black MH, Zhou H, Takayanagi M, Jacobsen SJ, Koebnick C. Increased asthma risk and asthma-related health care complications associated with childhood obesity. Am J Epidemiol. 2013;178(7):1120-8.

41. Burlingame B, Dernini S. Sustainable diets and biodiversity: directions and solutions for policy research and action. Rome, Italy: Food and Agriculture Organization; 2010.

42. Tilman D, Clark M. Global diets link environmental sustainability and human health. Nature. 2014;515(7528):518-22.

43. Richter BD, Bartak D, Caldwell P, Davis KF, Debaere P, Hoekstra $\mathrm{AY}$, et al. Water scarcity and fish imperilment driven by beef production. Nat Sustain. 2020;3(4):319-28.

44. Boehm R. Reviving the dead zone: solutions to benefit both gulf coast fishers and midwest farmers. 2020. https://www.ucsusa.org/ resources/reviving-dead-zone. Accessed 2 Jun 2020.

45. Haines A, Ebi K. The imperative for climate action to protect health. N Engl J Med. 2019;380(3):263-73.

46. Willett W, Rockström J, Loken B, Springmann M, Lang T, Vermeulen S, et al. Food in the Anthropocene: the EATLancet Commission on healthy diets from sustainable food systems. Lancet. 2019;393(10170):447-92.

47. Committee DGA. Scientific Report of the 2020 Dietary Guidelines Advisory Committee: advisory report to the Secretary of Agriculture and the Secretary of Health and Human Services. Washington, DC: U.S. Department of Agriculture, Agricultural Research Service; 2020.

48. Hirvonen K, Bai Y, Headey D, Masters WA. Affordability of the EAT-Lancet reference diet: a global analysis. Lancet Glob Health. 2020;8(1):e59-66.

49. Springmann M, Godfray HC, Rayner M, Scarborough P. Analysis and valuation of the health and climate change cobenefits of dietary change. Proc Natl Acad Sci USA. 2016;113(15):4146-51.

50. Tonstad S, Stewart K, Oda K, Batech M, Herring RP, Fraser GE. Vegetarian diets and incidence of diabetes in the Adventist Health Study-2. Nutr Metab Cardiovasc Dis. 2013;23(4):292-9.

51. Turner-McGrievy G, Mandes T, Crimarco A. A plant-based diet for overweight and obesity prevention and treatment. J Geriatr Cardiol. 2017;14(5):369-74.

52. Nelson ME, Hamm MW, Hu FB, Abrams SA, Griffin TS. Alignment of healthy dietary patterns and environmental sustainability: a systematic review. Adv Nutr. 2016;7(6):1005-25.

53. Springmann M, Wiebe K, Mason-D'Croz D, Sulser TB, Rayner M, Scarborough P. Health and nutritional aspects of sustainable diet strategies and their association with environmental impacts: a global modelling analysis with country-level detail. Lancet Planet Health. 2018;2(10):e451-61.

54. U.S. Energy Information Administration. Use of energy explained: energy use for transportation. 2021. https://www. eia.gov/energyexplained/use-of-energy/trans portation. php\#: : text $=$ Natural $\% 20$ gas $\% 2 \mathrm{C} \% 20$ as $\% 20$ compressed $\%$ 20natural,government $\% 20$ and $\% 20$ private $\% 20$ vehicle $\% 20$ fleets. Accessed 15 Dec 2021.

55. Kotchen MJ. The producer benefits of implicit fossil fuel subsidies in the United States. Proc Natl Acad Sci USA. 2021;118(14).
56. U.S. Energy Information Administration. How much tax do we pay on a gallon of gasoline and on a gallon of diesel fuel? 2021. https:// www.eia.gov/tools/faqs/faq.php?id=10\&t=10. Cited $11 \mathrm{Jul} 2021$

57. Duncan I. How the gas tax could help pay for a $\$ 1$ trillion infrastructure proposal. 2021. https://www.washingtonpost.com/transportation/ 2021/06/11/infrastructure-bill-gas-tax-faq/. Cited 11 Jul 2021.

58. Landrigan PJ, Fuller R, Acosta NJR, Adeyi O, Arnold R, Basu $\mathrm{NN}$, et al. The Lancet Commission on pollution and health. Lancet. 2018;391(10119):462-512.

59. Friedman MS, Powell KE, Hutwagner L, Graham LM, Teague WG. Impact of changes in transportation and commuting behaviors during the 1996 Summer Olympic Games in Atlanta on air quality and childhood asthma. JAMA. 2001;285(7):897-905.

60. Xiao C, Goryakin Y, Cecchini M. Physical activity levels and new public transit: a systematic review and meta-analysis. Am J Prev Med. 2019;56(3):464-73.

61. Heath GW, Brownson RC, Kruger J, Miles R, Powell KE, Ramsey LT, Task Force for Community Preventive Services. The effectiveness of urban design and land use and transportation policies and practices to increase physcial activity: a systematic review. J Phys Act Health. 2006;3(Suppl 1):S55-76.

62. Giles-Corti B, Vernez-Moudon A, Reis R, Turrell G, Dannenberg AL, Badland $\mathrm{H}$, et al. City planning and population health: a global challenge. Lancet. 2016;388(10062):2912-24.

63. Sallis JF, Cerin E, Conway TL, Adams MA, Frank LD, Pratt M, et al. Physical activity in relation to urban environments in 14 cities worldwide: a cross-sectional study. Lancet. 2016;387(10034):2207-17.

64. Woodcock J, Banister D, Edwards P, Prentice AM, Roberts I. Energy and transport. Lancet. 2007;370(9592):1078-88.

65. Bell JF, Wilson JS, Liu GC. Neighborhood greenness and 2-year changes in body mass index of children and youth. Am J Prev Med. 2008;35(6):547-53.

66. Frank LD, Sallis JF, Conway TL, Chapman JE, Saelens BE, Bachman W. Many pathways from land use to health: associations between neighborhood walkability and active transportation, body mass index, and air quality. J Am Plann Assoc. 2006;72(1):75-87.

67. The Rockefeller Foundation. True cost of food: measuring what matters to transform the U.S. food system. New York, New York: Rockefeller Foundation; 2021. This report from the Rockfeller Foundation emphasizes that the true costs of food must include the effects of their production on sustainability and climate change.

68. Dietary Guidelines Advisory Committee. Scientific Report of the 2015 Dietary Guidelines Advisory Committee. Washington, DC: Department of Health and Human Services and United States Department of Agriculture; 2015.

69. Vilsack T, Burwell S. 2015 dietary guidelines: giving you the tools you need to make healthy choices. 2017. https://www.usda.gov/ media/blog/2015/10/06/2015-dietary-guidelines-giving-you-toolsyou-need-make-healthy-choices. Accessed 13 Oct 2019.

70. Whitmee S, Haines A, Beyrer C, Boltz F, Capon AG, de Souza Dias BF, et al. Safeguarding human health in the Anthropocene epoch: report of the Rockefeller Foundation-Lancet Commission on planetary health. Lancet. 2015;386(10007):1973-2028.

71. Robinson TN. Save the world, prevent obesity: piggybacking on existing social and ideological movements. Obesity. 2010;18(Suppl 1):S17-22.

72. Leiserowitz A, Maibach E, Rosenthal S, Kotcher J, Carman J, Wang X, et al. Climate change in the American mind. New Haven, Connecticut: Yale University and George Mason Univesity; 2021.

73. Merrigan K, Griffin T, Wilde P, Robien K, Goldberg J, Dietz W. Designing a sustainable diet. Science. 2015;350(6257):165-6.

74. C40 Cities. C40 initiatives and networks. https://www.c40.org/ networks. Accessed 14 Jul 2021.

75. Climate Health Action. US call to action on climate health and equity: a policy action agenda 2019. https://climatehealthaction. org/. Accessed 22 July 2021. 
76. Watts N, Amann M, Arnell N, Ayeb-Karlsson S, Belesova K, Boykoff M, et al. The 2019 report of the Lancet Countdown on health and climate change: ensuring that the health of a child born today is not defined by a changing climate. Lancet. 2019;394(10211):1836-78.
Publisher's Note Springer Nature remains neutral with regard to jurisdictional claims in published maps and institutional affiliations. 